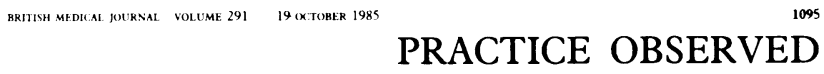

\section{Research in Progress}

\section{A new syndrome from general practice?}

D H JUDSON

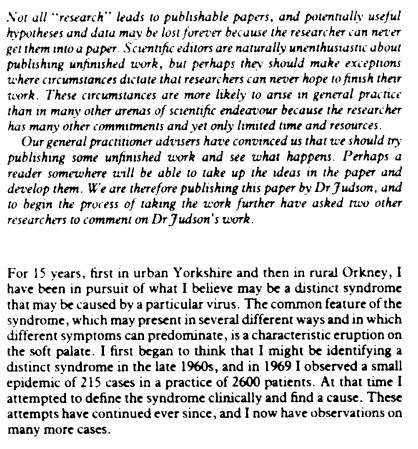

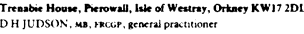
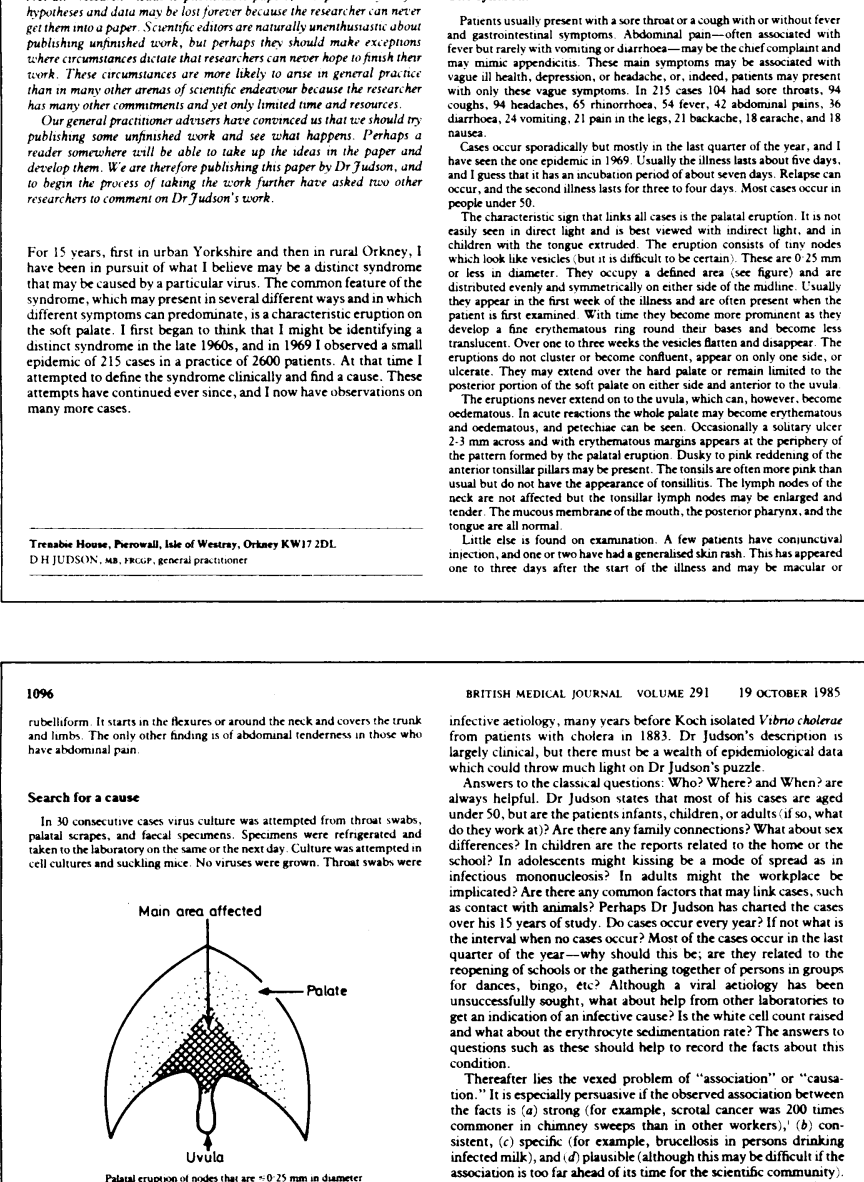

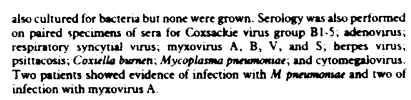

Discussion

After 15 years of work on this condition I have no prof that it is 2

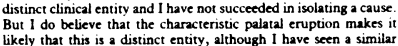

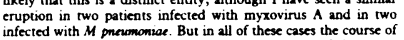

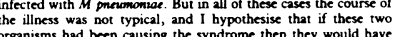

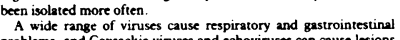

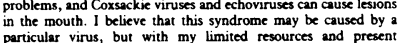

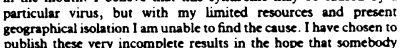

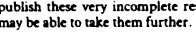

Da Danier RerD:

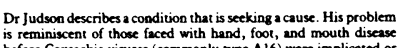

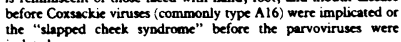
isoluted.
Before being sure char Dr Judson is describing a discinct clinical

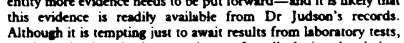

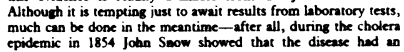

BRTTISH MEDICAL JOURNAL VOLUME $291 \quad 19$ OCTOBER 1985

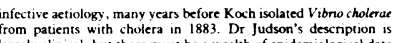
which could throw much light on Dr Juscon's puzzle.

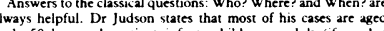

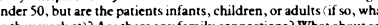

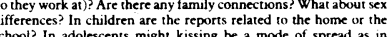

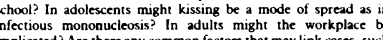

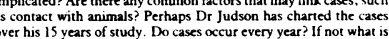

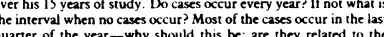
warter of the year - why should this be; are they related to the

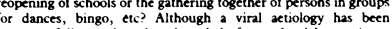

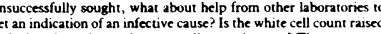

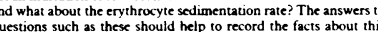

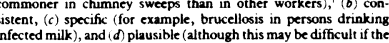

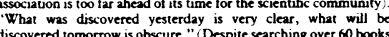

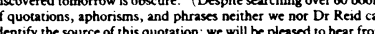

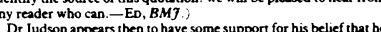

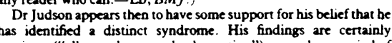

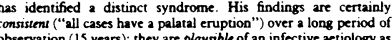

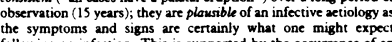

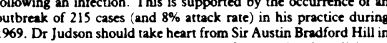

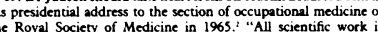

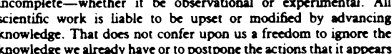

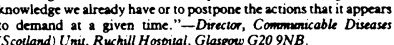

Refereacet

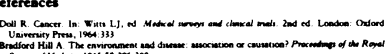
Da D w Maclear

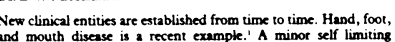

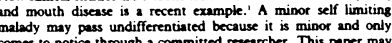

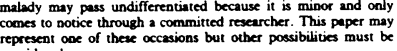

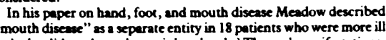

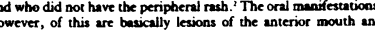

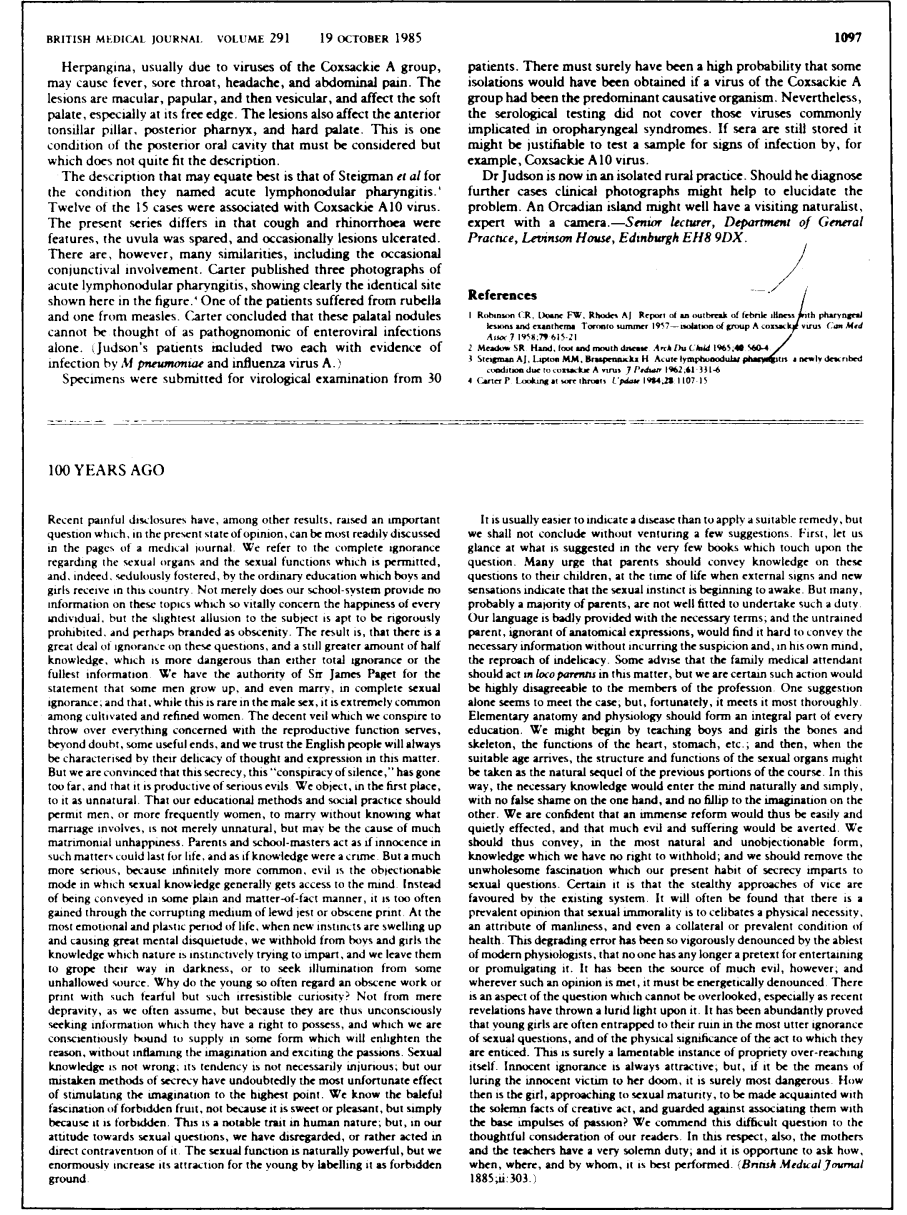

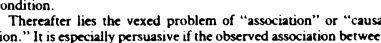

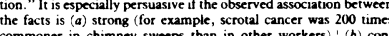

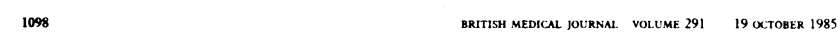

\section{Audit Reports}

Generic prescribing: hospital reports to a general practice

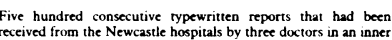

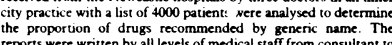

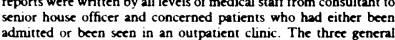

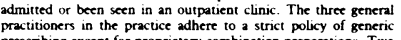

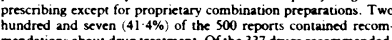

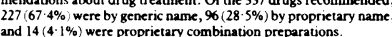

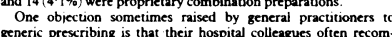

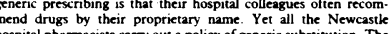

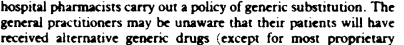

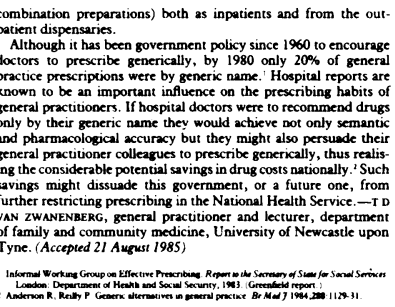

\section{Treatment of hypertension}

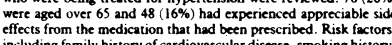

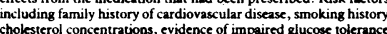

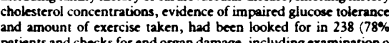

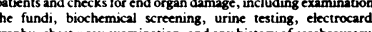

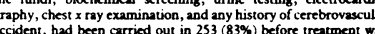

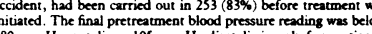

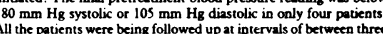

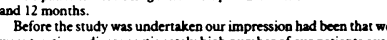

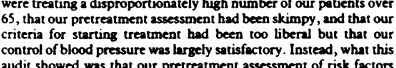

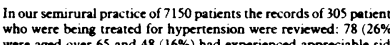

